\title{
Rituximab-Induced Acute Lympholysis and Pancytopenia After COVID-19 Vaccination
}

\author{
Yuankai $\operatorname{Lin}^{1}$ and Victoria Leung ${ }^{2}$ \\ ${ }^{1} \mathrm{UCSF}$ \\ ${ }^{2} \mathrm{VACCHCS}$
}

April 21, 2021

\begin{abstract}
Current guidelines do not adequately acknowledge the potential acute consequences in patients receiving both rituximab and COVID-19 vaccination. We report a case of rituximab-induced lympholysis and pancytopenia in a patient who received Moderna COVID-19 vaccine ten days before rituximab infusion. These observations highlight the urgent need to update current guideline.
\end{abstract}

\section{Hosted file}

Rituximab-Induced Lympholysis.pdf available at https://authorea.com/users/409199/articles/ 518963-rituximab-induced-acute-lympholysis-and-pancytopenia-after-covid-19-vaccination 